\title{
Tool Flank Wear Estimation using Emitted Sound Signal Analysis by PCA - SER Based Peak to Peak Measurements
}

\author{
K.Prakash , Andrews Samraj
}

\begin{abstract}
The higher levels degrees of automation for industry 4.0 standards require optimization techniques in production activities including tool wear monitoring. The unmonitored tool may spoil the product if it is worn out more than the permitted levels or micro broken or cracked internally. A novel method suggested in this work utilizes neither extra ordinary calculation nor complex mathematical transformations in tool wear monitoring. This method follows no video capturing and image processing rather follows a simple sound wave monitoring captured at the time conversion process by a microphone. The SER a PCA variant technique with the purpose of used in selecting simply the higher velocity of principal components (PCs) in quantifying the feature extracted while separating noise from sound signals. A SER method is used for the selection of suitable PCs for consideration. The best methods of normalization suitable for the SER method is found and implemented the PCA-SER on signals after filter the signals by butter worth filter to remove noise. This proposed procedure resulted in wide differences and proper annotation in differentiating the degree of tool wear in fresh, slight and severely worn categories.

Index Terms: Microphone, Tool Flank Wear, Selective Eigen Rate(SER), Principal Components.
\end{abstract}

\section{INTRODUCTION}

Industrial automation benefits and ensure flawless production quality in the products. As a part of automated monitoring, tool bits that works on CNC machines are checked for their integrity and condition during the production process periodically. In order to get optimum manufacturing benefits the tool wear condition has to be checked in proper intervals without affecting the machining process. High precision camera's to monitor the tool wear condition was one of the yester year technique which does not result in accurate measurements. The acquisition of process variable values like power used for cutting, amount of heat vibration, current for spindle motor current, surface roughness and their correlation to the tool wear were considered to monitor the tool wear indirectly considered. Researches like Alonso et.al [1] suggested a mechanism to predict the degrees of tool flank wear by artificial neural network that works on the sound signals emitted at the time of conversion procedure by considering feed cutting force. Sadettin et.al [2] establish the vibration of amplitude is

Revised Manuscript Received on October 30, 2019

* Correspondence Author

K.Prakash*, Department of Computer Applications, Mahendra Engineering College, Namakkal, Tamil Nadu , India.

Andrews Samraj, Department of Computer Science and Engineering, Mahendra Engineering College, Namakkal, Tamil Nadu, India.

(C) The Authors. Published by Blue Eyes Intelligence Engineering and Sciences Publication (BEIESP). This is an open access article under the CC BY-NC-ND license (http://creativecommons.org/licenses/by-nc-nd/4.0/) straightforwardly to the intensification tool wear. During the research of Ming-Chyuan et al [3] and Alonso F.J et al. the perceptible sound generated from the cutting method is used as the monitoring mechanism for the tool flank wear. A Samraj et al. [4] used a portion of emitted sound from the turning function to calculate the tool flank wear swiftly using active estimation cluster technique. Peng et al [5] suggested that the signal to be process should be linear momentarily stationary and linear; or else, the ensuing Fourier spectrum may produce significantly lower corporeal sense. According to Huang et al. [6] the Fourier transformation represents the global signal properties rather than local properties. Since it employs a convolution integral by which the signal is break down in conditions of cosine and sine function that covers the total data span uniformly. Wavelength transformation, time frequency analysis or used to generate time and frequency information of the one dimensional signal buy simultaneously mapping to a two dimensional time frequency plane. Lately Sick [7] an experienced researcher over a decade on online not direct tool wear monitor using artificial neural network concluded that it is possible to classify the parameter of tool wear using neural networks. As a comprehension a refined analysis of the emitted sounds while the conversion procedure to estimate the tool wear condition is the prudent method that augments any efficient automated manufacturing[8],[9]. The alternative like capturing images in videos and other monitoring devices causes expenses and erroneous predictions. The present paper has proposed a technique that deals with the estimation of wear from the recorded sound signals by subjecting them to a Selective Eigen Rate PCA. It is very important to extract the signal a lot of accurately with no damaging any suitable information hidden within the contaminated signal, and that's whereas proficient extraction techniques in Principal Component Analysis (PCA) like Selectively Eigen Rate are followed. The aim of this paper is to analyze the potency of the projected Selective Eigen Rate (SER) technique in choosing PCs for the valuable modernization of the noise signal that is particularly appropriate once the number of noise is incredibly high. SER's potential in choosing the suitable PCs for the efficient modernization of the supply signal. This work is a continuous enhancement of our previous works $[11,12]$

\section{EQUIPMENT SETUP AND METHODOLOGY}

\section{A The Hardware Setup}

An extensive amount of noise is generated during the time of conversion process due to the vibration generated from the work-piece and work machine tool. 


\section{Tool Flank Wear Estimation using Emitted Sound Signal Analysis by PCA - SER Based Peak to Peak Measurements}

At the time of estimation process the generated noise is anticipated with respect to the size, intensity and surface of contact to which the cutting insert occurred in flank wear [10]. In addition to that the other assorted vibrations may be produced in surroundings during the process of tool wear estimation. These interruptions occurred due to vibration can be segregated using suitable filters, which appears in low frequency its range falls between $0 \mathrm{kHz}$ to $2 \mathrm{kHz}$. Where upon the influence of this turning process is highly notable while this interruption reaches above the frequency range of 2 $\mathrm{kHz}$ level. The feature of sound pressure from generated sound wave is measured using condenser microphone. Figure 1 shows the microphone it tends to record the sound waves.

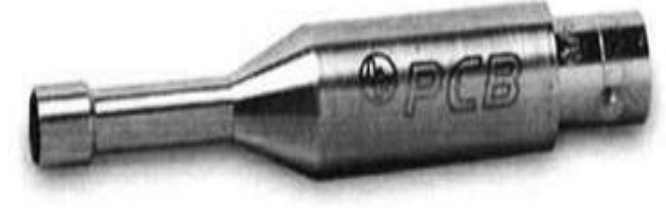

Figure 1. The Microphone used on the experiment to record sound (PCB 130 D 20)

The devices which are utilized in this experimental set up to record the noise of vibration is microphone which is $1 / 4$ " in its diameter and its marketable identification is PCB 130 D20. This microphone has a potential of recording a noise at the extent of $12 \mathrm{~dB}$ in dynamic range. This is the appropriate electro - acoustic transducer which records the noise during turning process which has outcome frequency responses from the range of $20 \mathrm{~Hz}$ to $20 \mathrm{kHz}$ and the exactness of noise varies $\pm 0.5 \mathrm{~dB}$. This microphone uses a BNC connector and great temperature resistant material which is manufactured by polymer is used, so the necessity of external polarization is wiped out, this process includes frozen electrical charges, implemented at the back plate in the top. This PCB 130 D 20 microphone is extensively used in sound power measurement and multi-channel machinery noise measurements. The planning and location of the microphone linked in the direction of measuring are shown in Figure. 2 during the machining method.

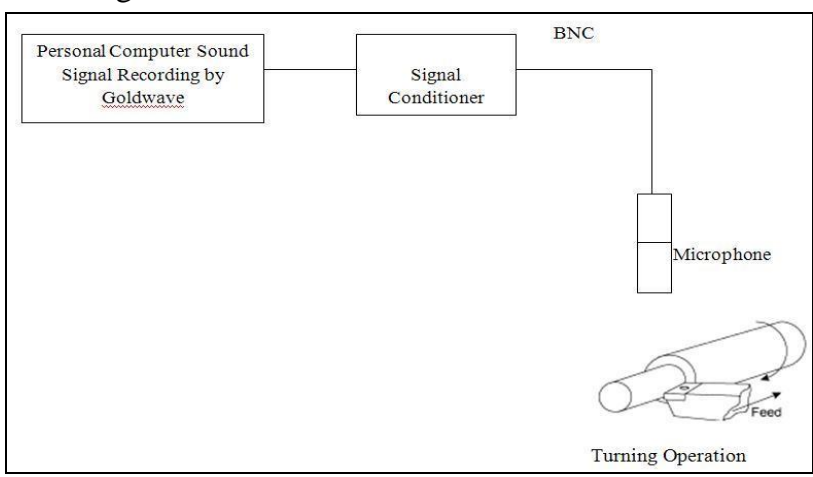

Figure. 2. The sound signal of tool wear data recording arrangement

\section{B. Classification of PCA Features}

The classifications of the PCA features from these three dissimilar noise recordings were disbursed through the straight forward lower dimensional set of tool inputs.

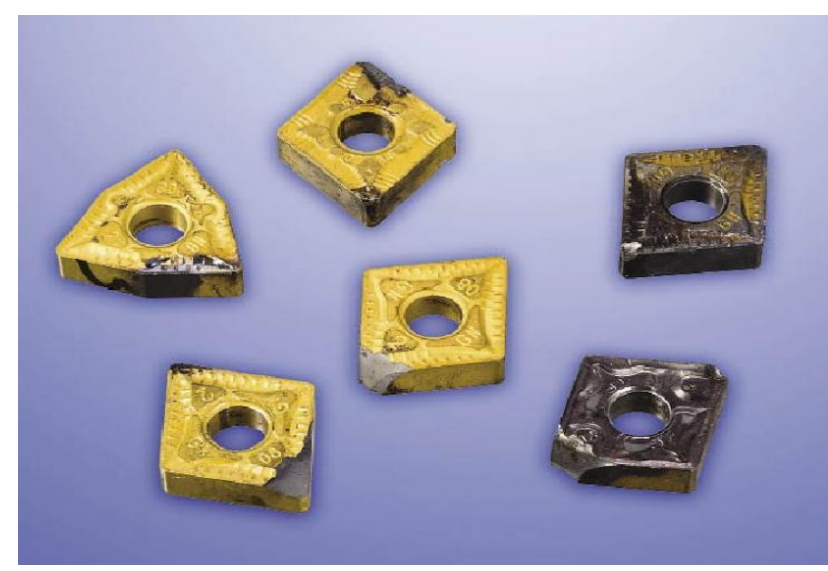

Figure.4. The different levels of tool wear

\section{Methods}

\section{Principal Component Analysis}

PCA to extract differentiation sound elements was disbursed. Primarily, the covariance of the signal $W$ was computed by

$$
\mathrm{R}=\mathrm{E}\left(\mathrm{W} \mathrm{W}^{\mathrm{T}}\right)
$$

Let $\mathrm{D}=\operatorname{diag}(\mathrm{d} 1 \ldots \mathrm{dn}), \mathrm{F}$ be the orthogonal matrix of Eigen vectors of $\mathrm{D}$ along with $\mathrm{R}$ is that the diagonal matrix of its Eigen values,. After that the principal components might be computed by,

$$
\mathrm{Y}=\mathrm{FT} \text { WT }
$$

Some of the PCs can represent the differentiation sound components. The selections of sound components instead of PCs from the overall PCs were allotted by four completely different ways that is SER. These selected sound components were then used in reconstruction (the remaining PCs were omitted), Anywhere the reconstructed soundl now contains only sound components. The modernization be completed by

$$
\mathrm{X}=\mathrm{FFT} \text { YYT }
$$

where the YY and FF corresponds to the chosen PCs and eigenvectors

\section{PC Selection - Selective Eigen Rate (SER)}

In Selective Eigen Rate, the Principal components choice starts from the highest eigen value and continues up to the limitation that the distinction among the normalized successive Eigen value shouldn't go beyond the select threshold value. After various experimental simulations, we fixed this value to 0.005 . We tend to found that the most excellent method for normalizing the obtained Eigen -values is by simple normalization:

\section{Normalised eigen value $=$ Received Eigen-value/total}

$$
\text { of all Eigen values. }
$$




\section{Different Normalization methods}

The normalization method is needed for all the Eigen values that represent principal components and is dispensed so as to stay away from the omission of every principal component throughout the choice method by selective eigen rate technique. Since this is to ensure the principal components represented by Eigen values which are found to be in a huge difference range between each other sound not be ignored in the process. Hence, it is necessary to normalize them to reduce the huge difference without affecting their significance

The three techniques obtainable for normalizing the principal components are as follows. The Eigen values of each and every one of the principal components are arranged in downward order before we have a tendency to do the normalization.

In Technique 1, the primary Eigen value that's having the highest rate is taken along with is worn to partition all the Eigen values offered.

\section{Normalized Eigen value $(\mathrm{N})=$ attained Eigen}

value / Maximum Eigen value

$$
\mathrm{N}=\mathrm{ex} / \mathrm{e} 1
$$

In Technique 2, each and every one of the Eigen values that we have the total and therefore the total is used to divide all the Eigen values to obtain the values normalized.

$$
\begin{gathered}
\text { Normalized Eigen value }(\mathrm{N})=\text { attained Eigen } \\
\text { value / Total of all Eigen values } \\
\mathrm{N}=\mathrm{ex} / \mathrm{eM}
\end{gathered}
$$

Where eM is the total of all Eigen values

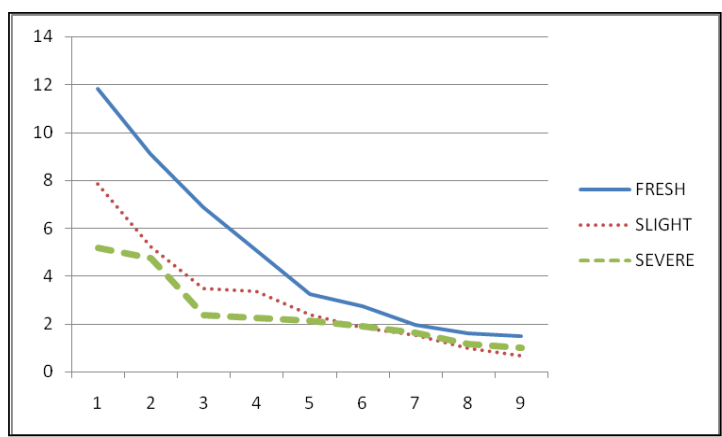

Figure 5. The Normalization method 2 of categories fresh, slight and severe wear tool sounds

In Technique 3, we come across the distinction between the successive Eigen values in addition to that value is divided by the corresponding Eigen value.

Normalized Eigen value $(\mathrm{N})=$ the diversity

between successive attained Eigen values / attained Eigen value

$$
\mathrm{N}=\mathrm{ex}-\mathrm{ex}+1 / \mathrm{ex}
$$

\section{RESULTS AND DISCUSSION}

The sound signal pieces S1 to S10 in each category were subjected to PCA based principal components selection method. The best normalized technique followed in process 2 mentioned in eqn 6 is followed on the signal pieces before the PC selection. The selected principal components for each signal piece were averaged and presented for all categories in table 1.

Table: 1 PCA features from three categories of sound signals

\begin{tabular}{|c|c|c|c|}
\hline & Sound & & \\
Signal Part & $\begin{array}{c}\text { Fresh tool } \\
\text { Aluminium }\end{array}$ & $\begin{array}{c}\text { Slight tool } \\
\text { Aluminium }\end{array}$ & $\begin{array}{c}\text { Severe tool } \\
\text { Aluminium }\end{array}$ \\
\hline S1 & -0.3864 & 1.1771 & 1.5605 \\
\hline S2 & 0.4452 & 0.3199 & -1.6169 \\
\hline S3 & 0.3217 & -3.0909 & 0.9732 \\
\hline S4 & 0.3944 & -1.6777 & -0.1477 \\
\hline S5 & -0.8886 & 1.0282 & -1.6383 \\
\hline S6 & -0.3121 & -2.3861 & 2.783 \\
\hline S7 & 0.1677 & -2.7644 & -1.424 \\
\hline S8 & -0.6695 & -1.3147 & 0.5893 \\
\hline S9 & -0.4841 & -3.3337 & 1.0038 \\
\hline S10 & 0.6726 & -3.5643 & -1.6225 \\
\hline Average & $\mathbf{- 0 . 0 7 3 9}$ & $\mathbf{- 1 . 5 6 0 7}$ & $\mathbf{0 . 0 4 6}$ \\
\hline $\begin{array}{l}\text { Maximum- } \\
\text { Minimum }\end{array}$ & $\mathbf{1 . 5 6 1 2}$ & $\mathbf{4 . 7 4 1 4}$ & $\mathbf{4 . 4 2 1 3}$ \\
\hline $\begin{array}{l}\text { Average }- \\
\text { Minimum }\end{array}$ & $\mathbf{0 . 8 1 4 7}$ & $\mathbf{2 . 0 0 3 6}$ & $\mathbf{1 . 6 8 4 3}$ \\
\hline $\begin{array}{l}\text { Maximum } \\
\text { Average }\end{array}$ & $\mathbf{0 . 7 4 6 5}$ & $\mathbf{2 . 7 3 7 8}$ & $\mathbf{2 . 7 3 7}$ \\
\hline
\end{tabular}

The associations are conducted along with the PCA features for the noise created through fresh and worn away tools of dissimilar degrees. The average of fresh tool wear PCA values differs from slight tool wear as well as severe tool wear. The differentiation between maximum average PCA value and minimum average PCA value is also presented. Again the difference between average of all averages in each category and the minimum PCA value average is also calculated and presented. Finally, the distinction between the average of all average PCA values and the maximum average PCA is also calculated for each category and tabulated. While there is a significant difference for each category there is no intonation pattern is found among the degree of tool wear in all these four calculations. So we decided to follow the analysis with improved PCA on each category to find the intonation pattern among the degrees of tool wear. The PCA- selective Eigen rate is a PCA variant that works differently in PC's selections. The PCASER used on the three categories of tool signals and found significantly improves the annotation of the principal component averages in the three categories. Figure 6, 7, and 8 shows the working of PCA-SER on raw signals sampled out of three categories. 

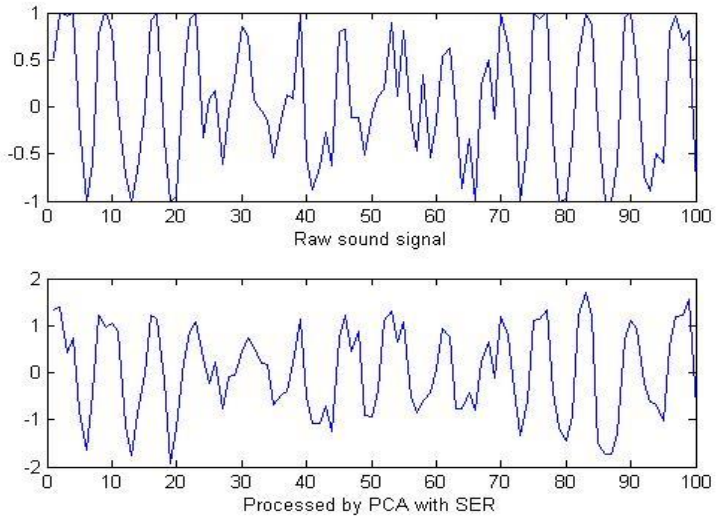

Figure 6. The processed PCA sound signals of fresh tool by PCA with SER
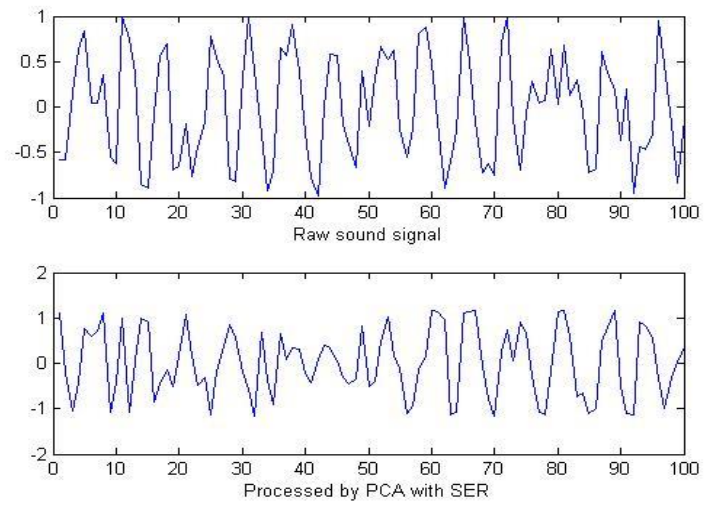

Figure 7. The processed PCA sound signals of slightly worn tool by PCA with SER
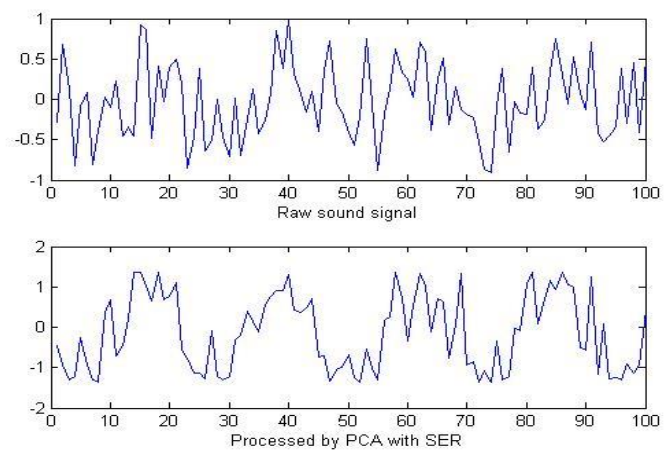

Figure 8. The processed PCA sound signals of severely worn tool by PCA with SER

The averages drawn from the PCA-SER for three different categories of tool wear are tabulated in table 2 were the annotation is found indirectly proportional to the tool wear.

Table: 2 The Peak values processed by PCA-SER tool categories of fresh, slight and severe

\begin{tabular}{|c|c|c|c|}
\hline $\begin{array}{c}\text { Sound } \\
\text { Signal } \\
\text { Part }\end{array}$ & $\begin{array}{c}\text { Fresh tool } \\
\text { Aluminium }\end{array}$ & $\begin{array}{c}\text { Slight tool } \\
\text { Aluminium }\end{array}$ & $\begin{array}{c}\text { Severe tool } \\
\text { Aluminium }\end{array}$ \\
\hline S1 & 0.79952 & 1.628 & 0.6946 \\
\hline S2 & 1.0405 & 1.1246 & 0.7323 \\
\hline S3 & 1.0265 & 0.9113 & 0.89 \\
\hline
\end{tabular}

\begin{tabular}{|c|c|c|c|} 
S4 & 1.0321 & 0.7842 & 0.6978 \\
\hline S5 & 0.7783 & 1.1061 & 0.9678 \\
\hline S6 & 0.9436 & 0.5121 & 1.2052 \\
\hline S7 & 1.0531 & 0.6005 & 1.0863 \\
\hline S8 & 0.9437 & 0.4975 & 0.9291 \\
\hline S9 & 1.2361 & 0.9815 & 0.9528 \\
\hline S10 & 1.1779 & 1.2336 & 1.0746 \\
\hline AVG & $\mathbf{1 . 0 0 3 1}$ & $\mathbf{0 . 9 3 7 9}$ & $\mathbf{0 . 9 2 3}$ \\
\hline
\end{tabular}

In order to further improve the annotation which gives wider gaps between the categories we introduced a butter worth filter on the raw signals the four we subject them for

$$
\text { PCA-SER process. }
$$

Table: 3 The Peak values processed by PCA-SER with filter tool categories of fresh, slight and severe

\begin{tabular}{|c|c|c|c|}
\hline $\begin{array}{c}\text { Sound } \\
\text { Signal } \\
\text { Part }\end{array}$ & $\begin{array}{c}\text { Fresh tool } \\
\text { Aluminium }\end{array}$ & $\begin{array}{c}\text { Slight tool } \\
\text { Aluminium }\end{array}$ & $\begin{array}{c}\text { Severe tool } \\
\text { Aluminium }\end{array}$ \\
\hline S1 & 0.8067 & 1.6442 & 0.6884 \\
\hline S2 & 1.1549 & 1.1421 & 0.7529 \\
\hline S3 & 0.9127 & 0.9336 & 0.9138 \\
\hline S4 & 1.045 & 0.829 & 0.6435 \\
\hline S5 & 0.909 & 1.0998 & 0.9201 \\
\hline S6 & 0.9748 & 0.5076 & 1.2131 \\
\hline S7 & 1.0383 & 0.6036 & 1.0564 \\
\hline S8 & 0.9328 & 0.5232 & 0.9028 \\
\hline S9 & 1.2229 & 0.9677 & 0.9459 \\
\hline S10 & 1.383 & 1.2222 & 0.9734 \\
\hline Avg. & 1.03801 & 0.9473 & 0.901 \\
\hline
\end{tabular}

This signals after filtering give further improved performance and is presented in table 3 .

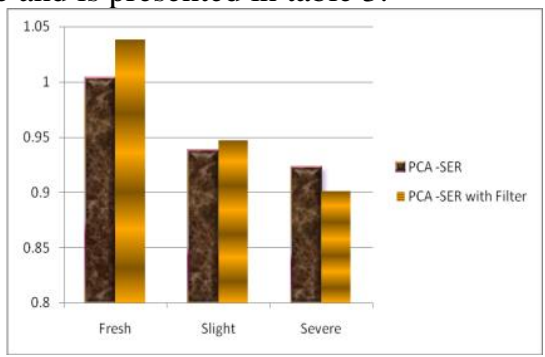

Figure 9. The peak value analysis by PCA-SER of raw signal and PCA-SER of filtered signal

The difference in degree of tool wear for fresh, slight and severe categories for PCA - SER and SER with filter of the emitted noise signals for high pitch and loudness is tabulated in table 4. 
Table 4: Differences in degree of tool wear for fresh, slight and severe categories for PCA-SER and SER with filter of the emitted sound signals for high pitch and loudness

\begin{tabular}{|l|l|l|l|}
\hline Category & \multicolumn{1}{|c|}{$\begin{array}{l}\text { Fresh } \\
\text { Slight }\end{array}$} & \multicolumn{1}{|l|}{$\begin{array}{l}\text { Slight } \\
\text { Severe }\end{array}$} & \multicolumn{1}{|l|}{$\begin{array}{l}\text { Fresh } \\
\text { Severe }\end{array}$} \\
\hline $\begin{array}{l}\text { PCA } \\
\text {-SER }\end{array}$ & 0.0652 & 0.0149 & 0.0801 \\
\hline PCA & & & \\
-SER \\
with \\
Filter
\end{tabular}

\section{CONCLUSION}

The best achievement in terms of difference and annotation is seen when the raw signals are applying preprocessing by the butter worth filter before applying to PCA - SER feature extraction method. The gap between tool wear categories were found increasing after the preprocessing. The proposed normalization method also helps to improve the performance and to achieve the better results. The combination of normalization preprocessing and feature extraction by PCA-SER helps to achieve the desired performance in distinguishing the degree of tool wear with proper annotation.

\section{REFERENCES}

1. F. J. Alonso and D. R. Salgado, "Application of singular spectrum analysis to tool wear detection using sound signals," Proc. IME, Part B: Journal of Engineering Manufacture, vol. 219, no. 9, pp. 703-710, 2005

2. Sadettin, O., S. Orhan, A. Osman Er, N. Camus-cu, and E. Aslan, "Tool wear evaluation by vibration analysis during end milling of AISI D3 cold work tool steel with 35 HRC hardness," NDT\&E International, vol. 40, pp. 121-126, 2007.

3. M. Chyuan Lu, E. Kannatey-Asibu, "Analysis of Sound Signal Generation Due to Flank Wear in Turning," Journal of Manufacturing Science and Engineering, vol. 124, no. 4, doi:10.1115/1.1511177, pp. 799-808, November 2002.

4. A. Samraj, S. Sayeed, J. Emerson Raja, J. Hossen, and A. Rahman, "Dynamic Clustering Estimation of Tool Flank Wear in Turning Process using SVD Models of the Emitted Sound Signals," World Academy of Science, Engineering and Technology, vol. 80, pp.1322-1326, 2011.

5. Z. K. Peng, Peter W. Tse, and F. L. Chu, "An improved Hilbert-Hung transform and its application in vibration signal analysis," Journal of Sound and Vibration, vol. 286, pp. 187-205, August 2005.

6. N. E. Huang, Z. Shen, S. R. Long, M. L. C. Wu, H. H. Shih, Q. N. Zheng, N. C. Yen, C. C. Tung and H.H. Liu, "The empirical mode decomposition and the Hilbert spectrum for nonlinear and non-stationary time series analysis," in Proc. Royal Society of LondonSeries A - Mathematical Physical and Engineering Sciences, 1998, pp. 903-995.

7. B. Sick, "On-line and indirect tool wear monitoring in turning with artificial neural networks: A review of more than a decade of research", Mechanical Systems and Signal Processing, vol. 16, no.4, pp.487-546, 2002.

8. J. Kopa, and S. Sali, "Tool wear monitoring during the turning process", Journal of Materials Processing Technology, vol. 113, Issues 1-3, pp. 312-316, 15 June 2001.

9. A. G. Rehorn, J. Jiang, and P. E. Orban, "State-of the art methods and results in tool conditioning monitoring: a review", International Journal of Advanced Manufacturing Technology,vol.26,pp.693-710,2005.

10. E. Dimla, and S. Dimla, "Sensor signals for tool-wear monitoring in metal cutting operations-a review of methods", International Journal of Machine Tools \& Manufacture, vol. 40, pp. 1073- 1098, 2000.

11. Prakash K, Samraj Andrews, Tool Wear Analysis by Acoustic Signal by Peak to Peak Analysis, International Journal of Mechanical Engineering and Technology, Volume: 9, Issue No: 11 pp. 1490-1500, 2018.

12. Prakash k, Samraj Andrews, "Tool Wear Condition Monitoring using Emitted Sound Signals by Acoustic - Electro Conversion", Journal of Scientific and Industrial Research, Vol. 78, August 2019.

\section{AUTHORS PROFILE}

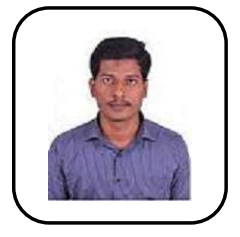

Mr.K.Prakash has completed Bachelor of Chemistry in 2006 from Periyar University and Master of Computer Applications in 2010 from Pallavan College of Engineering. He is pursuing Ph.D from Bharathiar University. His research interests are Image Processing, Signal Analysis, Machine Learning, Data Mining and Cloud Computing etc... He is currently working as Assistant Professor in Mahendra Engineering College, Namakkal, Tamilnadu, India. He has 9 years of Teaching Experience.

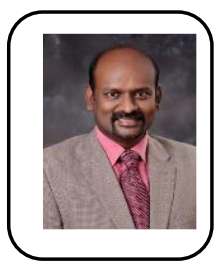

Prof.Dr.S.Andrews is the Professor of Computer Science and Engineering at Mahendra Engineering College, and renowned rehabilitation Engineering Scientist with Cybernetics and Wearable computing as his area of specialization. His Innovations in this area won the NASSCOM Social Innovation Forum Award 2017 in India. As a Lead scientist in Wearable Computing; he carries out his research in signals, cybernetics, control, robotics, assistive technology, affective computing and biomedical engineering. He completed his Ph.D from Multimedia University, Malaysia and done his post doctorate from WSEAS, Greece. 